\title{
ACCIDENT PREDICTION BASED ON INTEGRATED DESIGN CONSISTENCY WITH THE LOWER NUMBER OF VEHICLES/TRAFFIC VOLUMES (DUE TO HEALTH DISASTER/COVID-19)
}

\author{
${ }^{1}$ Joewono Prasetijo, ${ }^{2}$ Guohui Zhang, ${ }^{3}$ Muhammad Isradi, ${ }^{4}$ M. Ikhsan Setiawan, \\ ${ }^{5}$ ZaffanFarhana Zainal, ${ }^{6}$ Wan Zahidah Musa \\ ${ }^{1}$ Assistant Professor, Department of Transportation Engineering Technology,UniversitiTun Hussein Onn \\ Malaysia, 84600 Panchor, Johor,Malaysia \\ ${ }^{2}$ Associate Professor, Department of Civil and Environmental Engineering, University of Hawai'i at Manoa, \\ 2540 Dole Street, Honolulu, HI 96822, United States \\ ${ }^{3}$ Postgraduate Student, Faculty Engineering Technology, Universiti Tun Hussein Onn Malaysia, 84600 \\ Panchor, Johor, Malaysia \\ ${ }^{4}$ Department of Civil Engineering, Universitas Narotama, Surabaya 60213, JawaTimur \\ ${ }^{5,6}$ Department of Civil Engineering, Universitas Mercu Buana, Jatisampurna, Bekasi, Jawa Barat \\ 17433,Indonesia \\ Email: ${ }^{1}$ joewono@edu.uthm.my, ${ }^{2}$ guohui@hawaii.edu, ${ }^{3}$ isradi21@gmail.com, \\ ${ }^{4}$ ikhsan.setiawan@narotama.ac.id
}

\begin{abstract}
Purpose: Malaysia is one of the developing countries that facing high road accident in Asia. The most common accident happens is between motorcyclist and cars. A motorcyclist is 17 times more dangerous than passenger cars. Analysis shows the three main types of accidents in Malaysia is collision with passenger cars, collisions with other motorcycles and single-motorcycle accidents. Road accidents keep rising in Malaysia, because lacks of road geometric design consistency where the drivers make mistakes errors due to the road geometric features.

Design/methodology/approach: The study was conducted at F0050 from $\mathrm{km} 21$ until $\mathrm{km} 25$. By using GPS (DG -200), the continuous speed profile data were using new analysis method to develop road design consistency profile of motorcycle and cars and determined the value of the index the integrated road design consistency (IC).

Findings: The developments of consistency model are based on parameter: the bounded area between the profile and the average speed, standard deviation of speed along a segment. Hence, use ACAD software for develops consistency model's profile. The integrated-consistency model is the impact of the speed profile on design consistency in traffic and safety evaluations. The highest areas of an accident at $\mathrm{km} 24$ are justified based on the design consistency of the area and integrated design consistency model between of car and motorcycle is poor design. The study shows that crashes and fatalities are fully effected by traffic volumes but road design performances and driving behaviour.

Research limitations/implications: However, the traffic volumes are relatively low at the whole country regarding to the Movement Control Order (MCO) due to the pandemic COVID-19 since March 2020. In contrast with the reduction of the volumes, number of crashes still shows relatively high. Therefore, it shows that crashes and fatalities are influenced by other factors. Geometric factors such as access point, tangent length, curve length, shoulder width and lane width are influencing for an operating speed profile for a developed of tangents and curves of motorcycle and cars.

Practical implications: Result of this study can be used as references to solve accident problems in Malaysia. Paper type: This study is categorised as a case study.
\end{abstract}

Keywords: Development, Pandemic, Software

Accident Prediction Based On Integrated Design Consistency With The Lower Number

of Vehicles/Traffic Volumes(Due To Health Disaster/COVID-19)

Page | 287

Joewono Prasetijo, Guohui Zhang, Muhammad Isradi, M. Ikhsan Setiawan,

Zaffan Farhana Zainal, Wan Zahidah Musa 
Received: August $3^{\text {th }}, 2020$

Revised: September $14^{\text {th }}, 2020$

Published: September $30^{\text {th }}, 2020$

\section{INTRODUCTION}

Every year, mostly one million people are killed, three millions are severely disabled for life and thirty millions are injured in road accident according to WHO. Approaching 2020, road accident will be predicted to be the third important to contribute to the global burden of diseases and injury. Road accidents in Malaysia are the one of the fearsome issues when discussing the road traffic in this country. Malaysia is one of the developing countries that facing high road accident in Asia. About 30000 accidents reported and 1\% of its fatal accidents in Malaysia for every year. According to report from Royal Malaysia Police, the traffic accident in Malaysia has been increasing over the last three decades with an average rate of 9.7\% per annum. With the large volume of traffics on the road, accidents can happen by involving various types of vehicle (Abdullah and Zamri, 2012). The most common accident happens is between motorcyclist and cars. A motorcyclist is 17 times more dangerous than passenger car and also the motorcyclist will be in front of higher risk of injury or fatality because the level of exposure to injury is higher compared to a passenger car in an accident and also the risk of injury is estimated to be 12 higher than car passengers (Umar, 2005). Analysis shows that, the three main types of accidents in Malaysia is collision with passenger cars, collisions with other motorcycles and single-motorcycle accidents. Accidents that occur either car driver or motorcyclist was not injured, but the injured parties are either passengers or the occupants of the other vehicle around $97 \%$ of motorcyclist were injured or killed in these collisions compared with $50.5 \%$ of car drivers. It also stated that at high speed motorcycles and car collision than car and car collisions motorcyclist involved were $95.4 \%$ likely to be injured while car drivers were $0.9 \%$ likely to be (SMR et al., 2010).

Some research stated road accident happen because of driver fault, mechanical mistakes such as brake failure, tyre burst, etc. But the most road accidents happen because the road conditions itself (Abdullah and Zamri, 2012). Factor of road accidents keeps rising in Malaysia, because lacks of road geometric design consistency where the drivers make mistakes errors due to the road geometric features. If the consistency ispoor, the potential for accident happen are highest (Lamm, Psarianos and Mailaender, 1999).

\section{METHODOLOGY}

\section{A. Operating speed model $\left(85^{\text {th }}\right.$ percentile $)$}

Over the past 50 years, several models have been developed to predict the operating speed using geometric and traffic characteristics (Castro et al., 2008). Many studies developed using different data collection devices to estimate $85^{\text {th }}$ percentile speed on two lane rural road on horizontal curve and tangents for a variety of speed limits and type of vehicle. Most of the models developed are based on spot speed data collected at the specific locations and the speed measurement that had been used are radar gun, can give some inaccuracy because the reading angle is different from zero and drivers may reduce the speed.

Some researchers' determine the operating speed profile from the radius of circular curves, deflection angles, the relationship between curve length, etc. Previous study (Memon, Khaskheli and Dahani, 2012) only passenger vehicles operating under free flow condition were considered. Most of previous studied identified radius of the curve as influencing parameter in estimating operating speeds. Some study developed operating speed prediction models based on the continuous operating speed data collected through VBox.

\section{B. Design consistency model}

Design consistency is measured by estimating the speed variation along successive geometric elements and evaluation of the speed deviation from the average speed and in a road section result from geometric features and may cause drivers to make speed errors leading to higher collision risk (Memon, Khaskheli and Dahani, 2012). A road that has a good level of consistency can affect the driver to drive in a stable and careful. While for the poor level of consistency, can affect high speed along a different path among different drivers and can cause accidents (Prasetijo, Zainal and Musa, 2015).

Geometricdesigns are influenced by the vehicles, drivers and traffic characteristics. Geometric design elements that influence traffic operations include the number and width of lanes, the presence and widths of shoulders and highway medians, and the horizontal and vertical alignment of the highway. The most criteria 
used to evaluate design consistency are based on operating speed evaluation of the $85^{\text {th }}$ percentile speed of vehicles, and obtained by using operating speed prediction models. Some researchers have extended the concept by using continuous speed profiles (normalized area bounded of speed) to determine the speed variation along a road segment and determining a single consistency value for the whole road segment (Gibreel et al., 1999). Consistency evaluation methods are based on estimating the operating speed profile that's been used in other country including USA, Switzerland and Germany. According to (Mattar-Habib, Polus and Farah, 2008), purposed new methods to check design consistency. The parameters for this model are the bounded area between the profile and the average speed along a two-lane highway segment. As a design consistency increased, crash rates will shown to decrease significantly. The corresponding equations are

$$
R_{a}=\frac{\left(\sum a_{i}\right)}{L}
$$

where $R_{a}$ is relative area $(\mathrm{m} / \mathrm{sec})$ measure consistency, $\sum a_{i}$ is sum of $i$ areas bounded between the speed profile and the average operating speed $\left(\mathrm{m}^{2} / \mathrm{sec}\right), \mathrm{L}$ is entire segment length $(\mathrm{m})$

$$
\sigma=\left\{\frac{\left(V_{j}-V_{\text {avg }}\right.}{n}\right\}^{0.5}
$$

where $\Sigma$ is standard deviation of operating speeds $(\mathrm{km} / \mathrm{h}), V_{j}$ is operating speed along the $\mathrm{j}^{\text {th }}$ geometric element (tangent/curve) $(\mathrm{km} / \mathrm{h}), V_{\text {avg }}$ is average weighted (by length) operating speed along a segment $(\mathrm{km} / \mathrm{h}), \mathrm{n}$ is number of geometric elements along a segment $(\mathrm{km} / \mathrm{h})$

$$
V_{\text {avg }}=\frac{\sum V_{i} L_{i}}{\sum L_{i}}
$$

where $V_{a v g}$ is average weighted (by length) operating speed along a highway segment $(\mathrm{km} / \mathrm{h}), V_{i}$ is operating speed $(\mathrm{km} / \mathrm{h}), L_{i}$ is length of segment $(\mathrm{km})$.

The model of consistency (C) and the model integrated design consistency is [8]

$$
C=2.808 \cdot \exp ^{\left(-0.278 \cdot R_{a} \cdot \sigma\right)}
$$

Where $\mathrm{C}$ is basic consistency of a highway segment, $R_{a}$ is normalized area bounded by the average speed profile of cars/ motorcycle and the average operating speed $(\mathrm{m} / \mathrm{sec}), \sigma$ is standard deviation of cars speeds $(\mathrm{m} / \mathrm{sec})$.

$$
I C=\left[2.808 * \exp ^{\left(-0.278 * R_{a} * \sigma\right)}\right] * \exp ^{\left(-0.01 * A_{C T}\right)}
$$

where IC is integrated consistency of road sections, $R_{a}$ is normalized bounded area by speed profile of cars /motorcycle $(\mathrm{m} / \mathrm{sec}), \sigma$ is standard deviation of car speeds/ motorcycle, ACT is normalized bounded area between the speed profile of cars and motorcycle $(\mathrm{m} / \mathrm{sec})$.

\section{Data Collection}

The purpose of the study is to determine Performance Level of Road Geometric Design Based on Motorcycle - Cars Linear Speed Profile. The data collection can be determined based on location, type of vehicle, data speed of vehicles using global positioning system (GPS) and road features. The study was conducted on the Johor Federal Road (F0050), from km 21 until km 25 located in College Community Nurses BatuPahat until Taman Manis,Parit Raja,Johor,Malaysia. Figure 1 shows the location km21 until $\mathrm{km} 25$. 


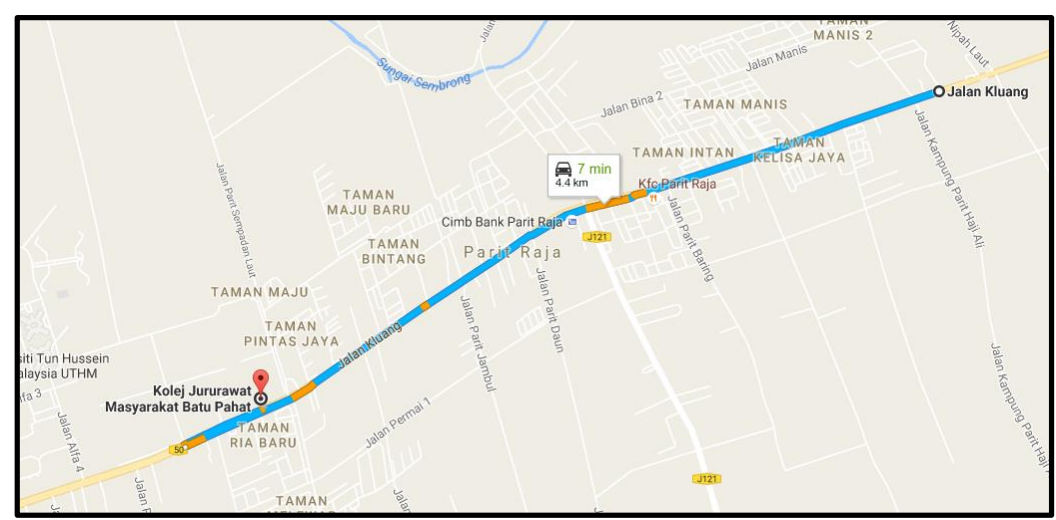

Fgure 1. Location km21-km25 (F0050)

Speed data collection (primary collection) along the selected segment was carried out by the test driver method at day time and under free flow and during off peak. The GPS DG-200 is being used in this study. GPS was placed into moving vehicles; cars and motorcycles, in which the two vehicles were used in this study. 100 test drivers and riders were instructed to drivers and riders along the selected segment by using the same vehicle. Speed data from signalized intersection been removed about $300 \mathrm{~m}$ to avoid the effect of traffic control devices on vehicle speeds and free flow speed (Prasetijo et al., 2020). The GPS device was configured to record the vehicle positions and speeds at one-second time intervals. Two persons, a driver and a GPS recorder, were needed to perform the data collection and the average vehicle travel speeds along distance traveled are being measured by GPS at every segment (Prasetijo et al., 2018). By using GPS, the continuous speed profile data were using new analysis method to develop road design consistency profile of motorcycle and cars and therefore determined value of the index the integrated road design consistency (IC).

Secondary collections are included data from accident data, traffic data and road features. The accident data collection was collected from data police that includes accident type, location and number of vehicles involving. Traffic data collection includes average annual daily traffic (AADT) that collected from authorities like Highway Planning Unit (HPU). Road Features include roads and road characteristics such as length of the tangent, length of curve, shoulder width, lane width and access point. The data were collected from authorities such as Public Ministry Work (JKR) or site visit. This study using Polus method (Polus and Mattar-Habib, 2004) to determine road design consistency model.

\section{RESULTS AND DISCUSSION}

\section{A. Development Operating Speed Model Tangent and Curve $\left(8^{\text {th }}\right.$ percentile $)$}

The models are developed based on the new method of speed profiles analysis. The profile was plotted based using continuous speed data obtained through GPS DG-200. $85^{\text {th }}$ percentile values were obtained from real speed and road elements through the analysis. By using statistical software (Minitab), the multiple linear regression method being used to develop the model for prediction of the $85^{\text {th }}$ percentile speed for the tangent and curve to develop prediction operating speed model for motorcycles and cars. Equation are developed using different variable such as the length of tangent, length of curve, shoulder width, lane width and access point. The following model shows that the number of vehicles/traffic volumes (AADT) were not contribute to the speed of V85. The statistical results are shows;

$$
\begin{array}{ll}
\text { Motorcycles } & \\
V_{85 t}=72.0+11.7 L_{t}+6.99 \mathrm{SW}-2.61 \mathrm{LW}+0.276 \mathrm{AP} & R^{2}=0.98 \\
V_{85 c}=20.6+102 L_{c}+4.16 \mathrm{SW}+0.82 \mathrm{AP} & R^{2}=0.79 \\
\text { Cars } & \\
V_{85 t}=88.9-1.26 L_{t}+27.4 \mathrm{SW}-16.9 \mathrm{LW}+1.07 \mathrm{AP} & R^{2}=0.99 \\
V_{85 c}=-31.1+202 L_{c}+4.1 \mathrm{SW}+1.38 \mathrm{AP} & R^{2}=0.83
\end{array}
$$


where $V_{85 t}=$ Operating speed of tangent, $V_{85 c}=$ operating speed of curve, $L_{t}=$ length of tangent, $L_{c}=$ length of curve, $\mathrm{SW}=$ shoulder width, $\mathrm{LW}=$ lane width, $\mathrm{AP}=$ access point.

\section{B. Validation of Models}

The validation of the developed models is carried out to verify the predictability of the model. Hence, scatter plot were plotted closed to the $45^{\circ}$ linebetween the observed speed and predicted operating speed model.The best fit linear relation between observed speed and predicted speed are shown in graph. Figure 2 shown comparisons observed speed vs. predicted speed of motorcycles at $\mathrm{km} 21$ until $\mathrm{km} 25$ while figure 3 shown comparisons observed speed vs. predicted speed of cars at km21 until km25.

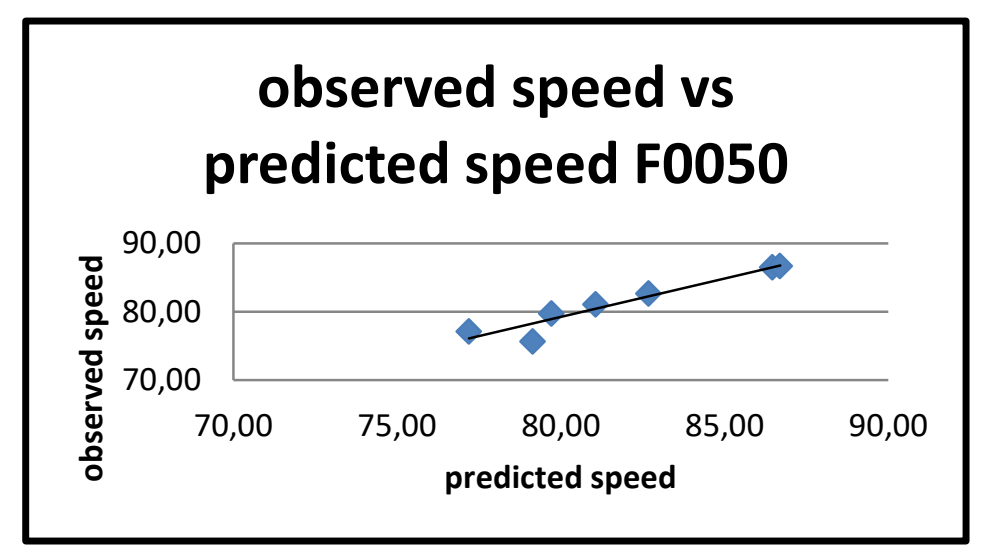

Figure 2. Comparison observed speed vs. predicted speed of motorcycles (KM21-KM25)

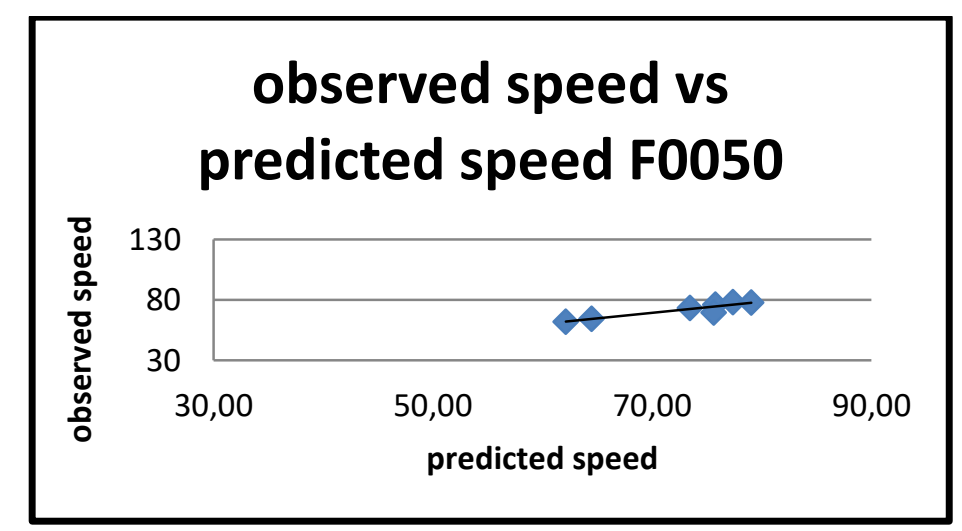

Figure 3. Comparison observed speed vs. predicted speed of cars (KM21-KM25)

\section{Development Design Consistency}

The design consistency was determined based on continuous operating speed profile models. To developed road design consistency model, ACAD software was used to developed road design consistency model. Plots of operating speed model profile (85th percentile) along the length are called asspeed profiles for this study. The graph line are represent operating speedmodel along the $j^{\text {th }}$ geometric element based on tangent and curve that have been developed early. Figure 4 shows speed profile F0050 of motorcycles at $\mathrm{km} 21-\mathrm{km} 25$. Figure 5 shows a speed profile F0050 of cars at $\mathrm{km} 21-\mathrm{km} 25$. The continuous operating speed profile models were plotted based on operating speed model $\left(85^{\text {th }}\right.$ percentile). 


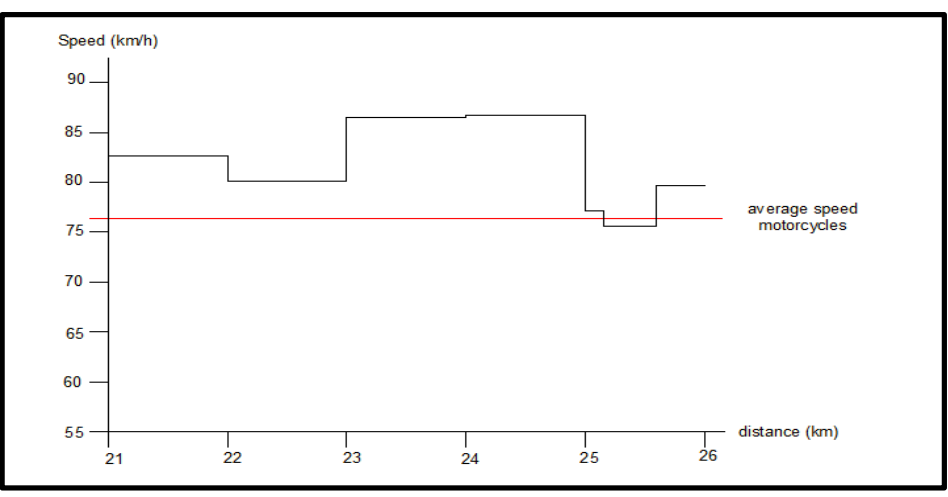

Figure 4.Speed profile F0050 of motorcycles (KM21 - KM25)

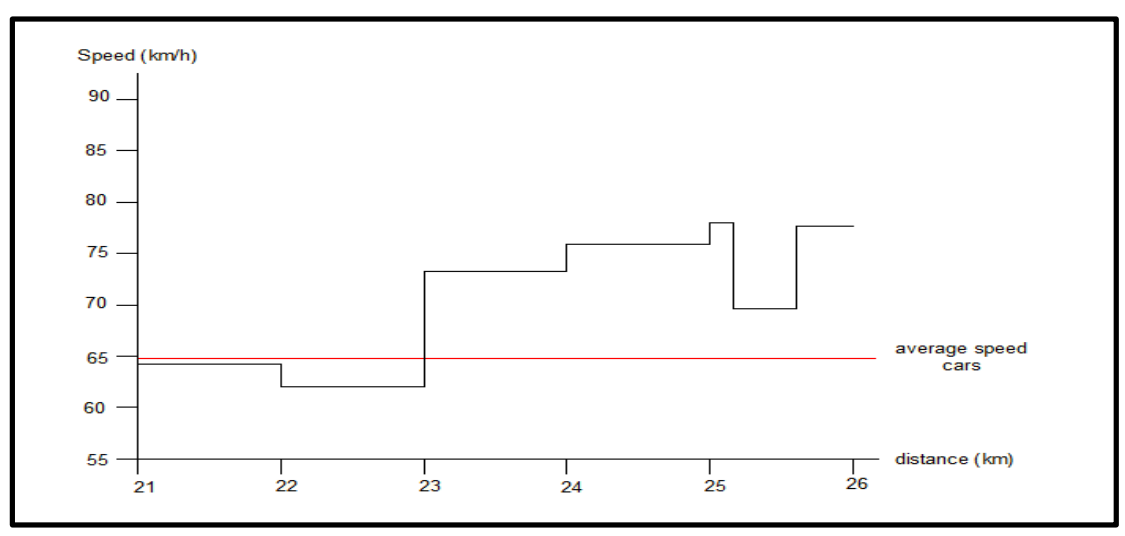

Figure 5. Speed profile F0050 of cars (KM21 - KM25)

The pattern shows the speed of motorcycles and cars in this roads segment depends on the environmental factors such as located of traffic lights, intersection and access point along segments, and it near to the shops and houses. Besides that, geometrics factors also affect the speed of motorcycles and cars such as shoulder width, lane width, and median and access point.

Based on a profile that has been developed, two main parameters for this model can be determined. The bounded area between the profile and the average speed and the standard deviation of speeds along a twolane highway segment was being calculated by using equation 1, 2 and 3 to determine design consistency for every segment per $\mathrm{km}$. Based on the two independent measures, a consistency model was developed by using equation 4. Table 1 shows design consistency motorcycles at $\mathrm{km} 21-\mathrm{km} 25$ per $\mathrm{km}$. Table 2 shows design consistency cars at $\mathrm{km} 21-\mathrm{km} 25$ per $\mathrm{km}$.

Table 1. Design consistency motorcycles (KM21 - KM25) per km

\begin{tabular}{lll}
\hline $\mathrm{Km}$ & Design Consistency & Threshold \\
\hline 21 & 1.02 & Acceptable \\
22 & 1.55 & Acceptable \\
23 & 0.55 & Poor \\
24 & 0.53 & Poor \\
25 & 2.10 & Good \\
\hline
\end{tabular}


Table 2. Design consistency cars (KM21 - KM25) per $\mathrm{km}$

\begin{tabular}{lll}
\hline $\mathrm{Km}$ & Design Consistency & Threshold \\
\hline 21 & 2.50 & Good \\
22 & 1.64 & Acceptable \\
23 & 0.55 & Poor \\
24 & 0.33 & Poor \\
25 & 0.46 & Poor \\
\hline
\end{tabular}

\section{Integrated Design Consistency Model}

An integrated-consistency model is needed as a function of speed profiles of cars and motorcycle. The model is included with the impact of speed profile of motorcycle on design consistency. Figure 6 shows a speed profile F0050 between motorcycles and cars at $\mathrm{km} 21-\mathrm{km} 25$. The normalized bounded area between the speed profiles motorcycles and cars can be determined through the speed profiles. Table 3 shows integrated design consistency between motorcycles and cars at km21 - km 25 per km. Every km shows value integrated design consistency and their threshold every $\mathrm{km}$. To determined integrated design consistency by using equation 5 .

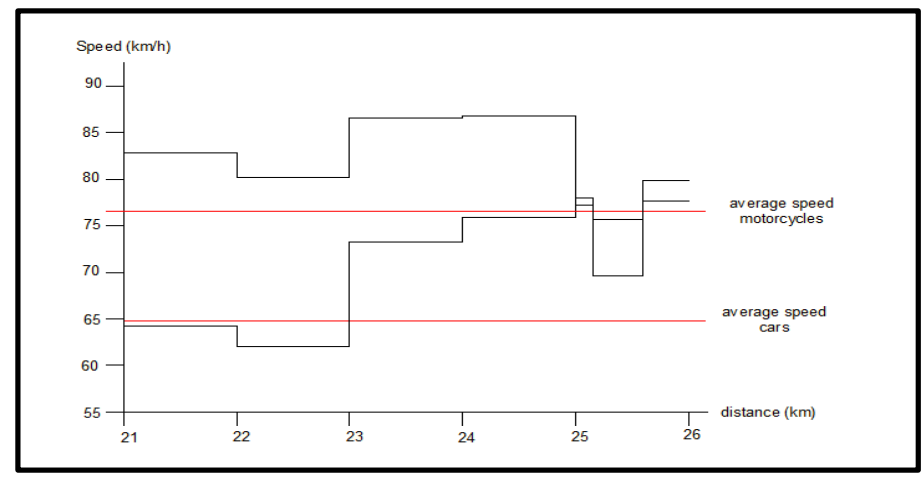

Fgure 6. Speed profile F0050 of motorcycles and cars (KM21 - KM25)

Table 3. Integrated Design consistency motorcycle and cars (KM21-KM25) per km

\begin{tabular}{llll}
\hline Km & Integrated Design Consistency & Threshold & APW \\
\hline 21 & 2.08 & good & 26.0 \\
22 & 1.37 & acceptable & 11.8 \\
23 & 0.48 & poor & 12.8 \\
24 & 0.30 & poor & 72.4 \\
25 & 0.45 & poor & 51.8 \\
\hline
\end{tabular}

This study is to develop a new model to estimate the consistency of segment at F0050. Based on two independent; the bounded area between the profile and the average speed and the standard deviation of speeds, it gave different approach to develop a model. Hence the consistency model is calculated for the selected segment, which is at $\mathrm{km} 21$ until $\mathrm{km} 25$.

The design consistency model was calculated about every $\mathrm{km}(\mathrm{km} 21$ until $\mathrm{km} 25)$. At $\mathrm{km} 21$, the threshold design consistency of motorcycles shows acceptable design, meanwhile design consistency of the cars shows good design. For the integrated design consistency motorcycle and cars, the threshold shows good design for both type vehicles.In this segments located of mosque, restaurants and junction along the way and access points along a road segments and no barrier median after signalized intersection can cause conflicts and accidents on the main road vehicles. At $\mathrm{km} \mathrm{22,} \mathrm{the} \mathrm{threshold} \mathrm{design} \mathrm{consistency} \mathrm{of} \mathrm{motorcycles} \mathrm{and}$ design consistency of the cars show acceptable. For the integrated design consistency motorcycle and cars, the threshold shows an acceptable design for both type vehicles. Even the design consistency is acceptable, the road have no median along a segment and can causes accident when vehicles from Ayer Itam stop immediately and cross to turn right and vehicles from BatuPahat to turn left, hence it cause conflict. 
At $\mathrm{km} 23$ and $\mathrm{km} \mathrm{24,} \mathrm{the} \mathrm{threshold} \mathrm{design} \mathrm{consistency} \mathrm{of} \mathrm{motorcycles} \mathrm{and} \mathrm{design} \mathrm{consistency} \mathrm{of} \mathrm{the}$ cars shows poor design. For the integrated design consistency motorcycle and cars, the threshold shows poor design for both type vehicles. Road geometry located at this area are not suitable to motorcycle and cars becauseit near to the shop, illegal parking at shoulder width can causes accident. Mostly a driver and motorcyclist drives high speed at this area. At $\mathrm{km} \mathrm{25}$, the threshold design consistency of motorcycles shows good design meanwhile design consistency of cars shows poor design, but for the integrated design consistency motorcycle and cars, the threshold shows poor design for both type vehicles. This segments tend high accident occurs because most drivers and motorcyclist travel as fast as they feel comfortable on straight section and reduce speed only when they come across the curve.

\section{CONCLUSION}

Based on the results and analysis, the conclusions of the result integrated design consistency between motorcycle and cars at $\mathrm{km} 21$ until $\mathrm{km} 25$ shows that the poor design consistency, hence the potential accident happens is higher. Even good design consistency, accident can occur. The segment along a road ( $\mathrm{km} 21-$ $\mathrm{km} 25$ ) consist many access point. Mostly vehicle from small junction crossing the road without hesitated and can cause accident on the main stream vehicle especially motorcycle and cars because not expecting vehicle from small junction. Design consistency was influenced the driver or motorcyclist to drive in a safe condition.Therefore, performance level of road geometric design based on motorcycle - cars are based through the result integrated design consistency between motorcycle - cars where the performance based on the thresholds values are differentiate among good, acceptable and poor design consistencies.

\section{ACKNOWLEDGMENTS}

The authors would like to thank the Universiti Tun Hussein Onn Malaysia for supporting the study through Fundamental Research Grant Scheme (FRGS) Grant Vot. 1452 (Ref: FRGS/1/2014/TK07/UTHM/02/2), Universitas Narotama and all individuals/organization that have made this study possible. Thank you is also extended to the Sustainable Transport and Safety Studies (STSS) Focus Group, Faculty of Engineering Technology, Universiti Tun Hussein Onn Malaysia.

\section{REFERENCES}

Abdullah, L. and Zamri, N. (2012) 'Road accident models with two threshold levels of fuzzy linearregression', Journal of Emerging Trends in Computing and Information Sciences, 3(2), pp. 225230.

Castro, M. et al. (2008) 'safety analysis using geographic information systems', in InProceedings of the Institution of Civil Engineers-Transport. Thomas Telford Ltd, pp. 91-97.

Gibreel, G. M. et al. (1999) 'State of the art of highway geometric design consistency', Journal of Transportation Engineering, 125(4), pp. 305-313. doi: 10.1061/(ASCE)0733-947X(1999)125:4(305).

Lamm, R., Psarianos, B. and Mailaender, T. (1999) Highway Design And Traffic Safety Engineering Handbook. New York: McGraw-Hill. Available at: https://trid.trb.org/view/503709 (Accessed: 21 October 2020).

Mattar-Habib, C., Polus, A. and Farah, H. (2008) 'Further evaluation of the relationship between enhanced consistency model and safety of two-lane rural roads in Israel and Germany', European Journal of Transport and Infrastructure Research, 8(4), pp. 320-332. doi: 10.18757/ejtir.2008.8.4.3360.

Memon, R. A., Khaskheli, G. B. and Dahani, M. H. (2012) Estimation of operating speed on two lane two way roads along N-65 (SIBI-Quetta), International Journal of Civil Engineering. International Journal of Civil Engineering. Available at: http://ijce.iust.ac.ir/article-1-516-en.html (Accessed: 21 October 2020).

Polus, A. and Mattar-Habib, C. (2004) 'New consistency model for rural highways and its relationship to safety', Journal of transportation engineering, 130(3), pp. 286-293.

Prasetijo, C., Zainal, F. Z. and Musa, Z. W. (2015) 'Speed Profile Based On Design Consistency', in In Proceedings International Conference on Engineering of Tarumanagara. Jakarta: Universitas Tarumanegara, pp. 78-80. 
Prasetijo, J. et al. (2018) 'Change of Road Integrated Design Consistency due to Antiskid Transverse Rumble Strips on High-Speed Federal Road FT050', Advances in Civil Engineering Materials, 7(3), p. 20170107. doi: 10.1520/ACEM20170107.

Prasetijo, J. et al. (2020) 'Crash model based on integrated design consistency with low traffic volumes (due to health disaster (COVID-19)/movement control order)', Innovative Infrastructure Solutions, 6(1), p. 22. doi: 10.1007/s41062-020-00388-7.

SMR, S. A. et al. (2010) 'Recent Trend of Fatal Motorcycle Crashes in Malaysia', in The 8th Int. Forum of Automotive Traffic Safety (INFATS). Wuhu. doi: 10.13140/2.1.3701.9845.

Umar, R. (2005) 'Ma Updates Of Road Safety Status In Malaysia', IATSS Research, 29(1), pp. 106-108. 